\title{
QUALITY OF LIFE AND NECK PAIN IN NURSES
}

\section{LUCY E. JOSLIN ${ }^{1}$, CHRISTOPHER R. DAVIS ${ }^{2}$, PATRICIA DOLAN³ ${ }^{3}$ and EMMA M. CLARK ${ }^{1}$}

${ }^{1}$ Southmead Hospital, Bristol, United Kingdom

Academic Rheumatology, Avon Orthopaedic Centre

${ }^{2}$ St. Thomas' Hospital, London, United Kingdom

Department of Plastic Surgery

${ }^{3}$ University of Bristol, Bristol, United Kingdom

Centre for Comparative and Clinical Anatomy

\begin{abstract}
Objectives: To investigate the association between neck pain and psychological stress in nurses. Material and Methods: Nurses from the Avon Orthopaedic Centre completed 2 questionnaires: the Short Form-36 (SF-36) and 1 exploring neck pain and associated psychological stress. Results: Thirty four nurses entered the study (68\% response). Twelve (35.3\%) had current neck pain, $13(38.2 \%)$ reported neck pain within the past year and $9(26.5 \%)$ had no neck pain. Subjects with current neck pain had significantly lower mental health (47.1 vs. 70.4; $p=0.002)$, physical health $(60.8$ vs. $76.8 ; p=0.010)$ and overall SF-36 scores (56.8 vs. 74.9; $p=0.003)$. Five (41.7\%) subjects with current neck pain and $5(38.5 \%)$ subjects with neck pain in the previous year attributed it to psychological stress. Conclusions: Over $1 / 3$ of nurses have symptomatic neck pain and significantly lower mental and physical health scores. Managing psychological stress may reduce neck pain, leading to improved quality of life for nurses, financial benefits for the NHS, and improved patient care.
\end{abstract}

Key words:

Stress, Nurses, Neck pain, Quality of life, SF-36

\section{INTRODUCTION}

Neck pain is a common musculoskeletal symptom with a lifetime prevalence of $71 \%$ [1] in Finland and an annual incidence of 34\% in the United Kingdom (UK) [2]. Incidence of neck pain is increasing [3] and it is estimated that up to $50 \%$ of the population have experienced neck pain in the past 12 months [4], with $29 \%$ of the UK population reporting neck pain over the past month [5]. Middle age and female gender are associated with risk factors for the development and reporting of neck pain [1,2,6-8]. Occupation is a risk factor for the development and duration of neck pain, with differences in work absenteeism according to the type of work [9]. Healthcare workers, including nursing staff, have the highest incidence of neck pain $[10,11]$ with $5.5 \%$ of working days lost each year due to neck pain [9]. This is greater than in physically demanding occupations including mining and transport building, where $2.4 \%$ and $3.7 \%$ of working days, respectively, are lost due to neck pain [9].

Musculoskeletal pain is an indicator of an individual's ability to work over the subsequent 2 years, therefore the symptom of neck pain has immediate and longer term consequences [12]. Nurses have reported low back pain associated with certain manual handling positions including axial rotation of the trunk and increased back pain linked to the prolonged duration of these positions [13].

Received: October 22, 2013. Accepted: January 22, 2014.

Corresponding author: L.E. Joslin, Academic Rheumatology, Avon Orthopaedic Centre, Southmead Hospital, Bristol, BS10 5NB, United Kingdom (e-mail: emma.clark@bristol.ac.uk). 
Some reduction in the prevalence of neck and back pain in nursing staff has already been achieved through education about safe physical handling of patients [14].

Psychological stress exacerbates physical stresses [6] and is associated with absence from work [15]. Female healthcare workers with increased occupational psychological stress were found to have poorer mental health [16]. The mental health of a patient with musculoskeletal symptoms is therefore a predictor of tendency to report pain and seek treatment [17] and influences the frequency of the General Practitioner consultations [17]. Furthermore, depression has been associated with increased pain intensity [18].

The aim of this study was to investigate the relationship between neck pain and psychological parameters in nursing staff. We hypothesize that mental health scores will be reduced in nurses with neck pain, and that nurses will demonstrate strong beliefs that neck pain and physical health are linked to psychological stress.

\section{MATERIAL AND METHODS}

This cross-sectional questionnaire-based study was carried out at the Avon Orthopaedic Centre, Bristol, United Kingdom. Two questionnaires were used, the SF-36 and a questionnaire focusing on subject demographics and clinical and individual views on neck pain. The SF-36 questionnaire is a validated general health survey for testing mental and physical health during the previous 12 months, and has been used to quantify musculoskeletal pathology [19]. Three scores can be derived from the SF-36 questionnaire: the mental health score, the physical health score and the overall general health score. The highest an individual can score in the SF-36 is 100 , with higher scores indicating better health [20].

\section{Ethics}

NHS ethical approval was granted by the Southmead Regional Ethics Committee, Bristol, UK (09/H0102/36).

\section{Study population}

All nursing staff from all 5 musculoskeletal wards were invited to enter the study via a poster conspicuously positioned in the communal staff rooms on each ward. These were frequented by all staff during formal handover meetings at the beginning and end of every shift, where the poster was highlighted to all staff. Staff also visited the room during break periods. The poster directed nurses to study packs. Each study pack contained both questionnaires, a participant information leaflet and a consent form. Study packs were distributed to all musculoskeletal wards in the Avon Orthopaedic Centre in order to maximize exposure, include all potential responders and provide a representative data sample.

Study participants completed anonymous questionnaires and returned them via sealed envelopes in the complementary and confidential internal mail system to the research office. On receipt of the completed consent form and questionnaires, each participant was allocated a unique number that was stored in a separate database to maintain confidentiality and permit blinded analyses. This number was recorded on all the paperwork to maintain the anonymity of study participants. Subsequent analyses were therefore carried out by a blinded researcher.

\section{Outcome measures}

The primary outcome was either current neck pain, neck pain in the previous 12 months or no neck pain. The secondary outcomes were the mental, physical and overall health scores in the SF-36; subjects' reporting and perceptions of psychological stress; and subjects' identification of a trigger for their neck pain.

The exposure measures were: current neck pain and neck pain during the past 12 months. Subjects were asked if they could identify a trigger for their neck pain and if they believed that there was an association between neck pain and psychological stress. Sociodemographic data, including age and sex, were also collected for each subject. 


\section{Sample size calculation}

The mean overall SF-36 score in the population is 50 with a standard deviation (SD) of 10 [19]. A change of 1SD from the mean is significant in the SF-12, a condensed version of the SF-36 [21]. Therefore, assuming subjects with neck pain would have a 1SD decrease in their overall SF-36 score, for $80 \%$ power a sample size of 32 subjects was required at the $95 \%$ level of probability.

\section{Statistical analysis}

Two-tailed t-tests were used to identify differences in the mean mental health scores between subjects with and without current neck pain and between subjects with and without a history of previous neck pain in the last 12 months. Non-parametric data were analyzed using Mann-Whitney tests. Subjects were categorized into 3 age groups (20-34 years, 35-49 years and 50-64 years). Normally distributed data were analyzed using one-way analysis of variance (ANOVA). Significance was accepted at $\mathrm{p}<0.05$, with $95 \%$ confidence intervals.

\section{RESULTS}

Thirty four members of the nursing staff team completed the questionnaires (68\% response). The sociodemographic data are displayed in Table 1. All the responders fully completed the study pack, with the exception of 1 subject who did not disclose their age.
Table 1. Sociodemographic data for the study group

\begin{tabular}{lcc}
\hline \multirow{2}{*}{ Characteristic } & \multicolumn{2}{c}{ Females } \\
\cline { 2 - 3 } & $\mathrm{n}$ & $\%$ \\
\hline Age (years) & 32 & 94.1 \\
$20-34$ & 11 & 32.4 \\
$35-49$ & 13 & 38.2 \\
$50-64$ & 9 & 26.5 \\
\hline
\end{tabular}

The results below are split according to 5 variables: current neck pain, previous neck pain, identifiable trigger, beliefs, and age/gender.

\section{Current neck pain}

Current neck pain was reported by $35.3 \%$ (12/34) of the subjects. Compared to asymptomatic colleagues, the subjects with current neck pain had significantly lower mean mental health scores, lower physical health scores and lower overall SF-36 scores (Table 2).

\section{Previous neck pain (pain in the last 12 months)}

Thirteen of the subjects (38.2\%) reported previous neck pain. Mental health, physical health and overall SF-36 scores were not affected by previous neck pain (Table 2).

\section{Trigger}

Out of the 25 subjects with current or previous neck pain, $19(76 \%)$ identified a specific trigger. Nine attributed their neck pain to stress, at work or at home, 5 attributed their neck pain to lifting and manual handling of patients.

Table 2. Short Form-36 (SF-36) questionnaire scores in the study group

\begin{tabular}{|c|c|c|c|c|c|c|c|c|c|}
\hline \multirow[t]{2}{*}{ Study group } & \multicolumn{2}{|c|}{$\begin{array}{l}\text { Mental health score } \\
(\mathrm{M} \pm \mathrm{SD})\end{array}$} & \multirow[t]{2}{*}{$\mathrm{p}$} & \multicolumn{2}{|c|}{$\begin{array}{l}\text { Physical health score } \\
\qquad(\mathrm{M} \pm \mathrm{SD})\end{array}$} & \multirow[t]{2}{*}{$\mathrm{p}$} & \multicolumn{2}{|c|}{$\begin{array}{c}\text { Overall SF-36 score } \\
(\mathrm{M} \pm \mathrm{SD})\end{array}$} & \multirow[t]{2}{*}{$\mathrm{p}$} \\
\hline & yes & no & & yes & no & & yes & no & \\
\hline Current neck pain & $47.1 \pm 23.6$ & $70.4 \pm 14.3$ & 0.002 & $60.8 \pm 15.7$ & $76.8 \pm 17.2$ & 0.010 & $56.8 \pm 14.6$ & $74.9 \pm 13.6$ & 0.002 \\
\hline Previous neck pain & $66.8 \pm 15.5$ & $75.9 \pm 11.0$ & 0.767 & $75.7 \pm 19.5$ & $78.6 \pm 13.5$ & 0.168 & $73.2 \pm 15.1$ & $77.8 \pm 11.2$ & 0.090 \\
\hline $\begin{array}{l}\text { Subject can attribute } \\
\text { neck pain to a trigger }\end{array}$ & $54.5 \pm 20.0$ & $64.7 \pm 27.6$ & 0.271 & $64.5 \pm 18.9$ & $83.4 \pm 10.9$ & 0.046 & $61.5 \pm 15.6$ & $79.3 \pm 14.3$ & 0.032 \\
\hline
\end{tabular}

M - mean; SD - standard deviation. 
The subjects who could attribute their neck pain to a particular trigger had similar mental health scores, but significantly lower physical health scores and lower overall SF-36 scores than those without a trigger (Table 2).

\section{Beliefs concerning the effects of psychological stress on pain and physical health}

Eleven of the 25 subjects with neck pain associated it with psychological stress. However, there was no significant difference in the mean mental health, physical health or overall SF-36 scores in these subjects compared to subjects who did not associate their neck pain with psychological stress -57.3 vs. $56.8(\mathrm{p}=0.954), 69.7$ vs. 67.8 ( $p=0.819), 65.8$ vs. $65.1(p=0.920)$, respectively. 33/34 $(97.1 \%)$ subjects believed that there was an association between psychological stress and physical health.

\section{Age and gender}

There was no significant difference in the mean mental health, physical health and overall SF-36 scores of subjects of different ages with previous neck pain $(\mathrm{p}=0.305)$ and without previous neck pain (0.992); comparisons between subjects of different ages with current neck pain and no neck pain were not undertaken as the data sample was to small to analyze the groups. No difference in results was found when analyses were split by gender.

\section{DISCUSSION}

This is the first study to investigate the association between neck pain and psychological stress in nursing staff on orthopedic surgical wards. The findings demonstrate that the prevalence of neck pain amongst such hospital staff is high: $35.3 \%$ of subjects reported current neck pain, and an additional $38.2 \%$ of subjects reported experiencing neck pain in the last 12 months. These findings are considerably higher than those reported in a previous study of neck pain in the general population, which found chronic neck pain to be prevalent in $5.9 \%$ of the population [5]. The findings also support our hypotheses: nurses with current neck pain have lower mental health scores, as well as reduced physical health and overall SF-36 scores, compared to those without neck pain, and a large proportion of these (44\%) associate their pain with psychological stress.

Furthermore, $97 \%$ of the total study population believe that physical health is influenced by psychological stress. The results of this study demonstrate that there is an association between neck pain and psychological health.

A prospective study in nurses found that a poor working relationship with colleagues was linked to a higher risk of future back pain [21], whilst in office workers, less interaction with other employees was associated with a decreased risk of developing upper back complaints [22]. These findings suggest that interactions with work colleagues may increase the risk of developing musculoskeletal symptoms, especially when team relationships are poor, and this might contribute to the high risk of neck pain in nurses who must interact on a regular basis with patients and other members of the healthcare team.

A related factor that may contribute to psychological stress and musculoskeletal symptoms is job satisfaction. Increased prevalence of neck and back pain has been found in nursing staff who feel dissatisfied with their employers and in those that are subject to high workplace demands [17]. Nursing roles with increased stimulation have been associated with a lower incidence of musculoskeletal complaints [23]. In addition, increased absence from work in nurses has been associated with perceived lack of support and encouragement [24].

Evidently, there are many factors that may increase psychological stress in the workplace, and the current results confirm that nursing staff with lower mental health scores are more likely to suffer from neck pain. Nevertheless, nurses in this study had good 'mental' health, compared to the general population where average scores are generally between 40 and 60 [19]. These findings suggest that the results 
may be influenced by the 'healthy worker effect' [25], and that nurses in the current study are less likely to have a history of mental health problems associated with poor physical health compared to the general population. Such an effect may also explain the findings observed in nurses who identified a trigger for their neck pain. These subjects had lower physical health and overall SF-36 scores than those who could not identify a trigger, but showed no reduction in mental health scores even though most of them attributed the trigger to a psychological rather than physical cause. This raises the possibility that nurses in this study were particularly good at adopting coping strategies to deal with low levels of psychological stress.

Female gender and ages 35-54 are identified as risk factors for neck pain [9]. Thirty two of the subjects (94.1\%) of our study population were female and 17/34 (50\%) subjects of our study population were between the ages of 35-54 years; therefore our finding that over $1 / 3$ of our study population reported current neck pain, with a further $1 / 3$ reporting neck pain in the past 12 months is not surprising.

Despite the generally good levels of mental health in our study population, most subjects $(97 \%)$ believed that physical health was affected by psychological stress and 10/25 (40\%) subjects with neck pain associated their pain with psychological stress. Furthermore, mental health scores were significantly reduced in those subjects who reported current pain suggesting a possible role for psychological interventions in an attempt to minimize neck pain in this patient group.

This study had some limitations, one of which was the small number of male subjects. Only 2 of the 34 nurses studied were men, so the results are not representative of neck pain and psychological stress in men. However, when the statistical analysis was repeated to remove the 2 male subjects, the results did not change, thus confirming the findings for female nursing staff. This study also found no effect of age on mental health, physical health and overall
SF-36 scores, which may reflect the small number of subjects in each age group. A larger sample size with more subjects of different ages may have demonstrated some age-related effects.

Further study limitations include response and recall bias and chance. Subjects in this study were self-selected, which may have given rise to response bias. However, 10 subjects in the study had not suffered from neck pain in the preceding 12 months. This demonstrates that self-selecting responders were not just those staff members who suffered from neck pain, but were a diverse clinical mixture. As the SF-36 asks about a subject's health over the past 12 months, there was the possibility of recall bias in this study. This may have resulted in false positives and negatives, but this is likely to reduce the strength of any association towards the null, rather than create inaccurate associations.

Important advantages of our study include recruitment of a well-defined group of nurses from musculoskeletal surgical wards in whom working conditions, and hence physical work load, would be quite similar. This should help to minimize any confounding influences of mechanical loading on pain, enabling associations with other factors such as psychological stress to be evaluated. The use of the SF-36 questionnaire, a validated and standardized questionnaire for assessing morbidity associated with spinal disorders [17], also enables direct comparison of the findings of this study with those obtained in other occupational groups.

Staff should be encouraged to maximize their mental health and consider the effect of psychological stress on their general health and well-being and how this may affect the patient care they provide.

\section{CONCLUSIONS}

Prevalence of neck pain amongst nursing staff is high, with approximately $1 / 3$ currently experiencing neck pain, and $2 / 3$ experiencing neck pain in the previous 
year. Neck pain is associated with lower mental health, physical health and overall SF-36 scores suggesting that management of psychological stress may be beneficial in the prevention and treatment of neck pain in this occupational group. Such an approach may ultimately offer financial savings for the NHS, improve the quality of life of nurses, and increase the standard of care they provide for their patients.

\section{ACKNOWLEDGEMENTS}

We would like to thank Professor Gordon Bannister for his generous advice, expert knowledge and selfless leadership with this manuscript.

\section{REFERENCES}

1. Makela M, Heliovaara M, Sievers K, Impivaara O, Knet P, Aromaa A. Prevalence, determinants, and consequences of chronic neck pain in Finland. Am J Epi. 1991;134:1365-7.

2. Palmer K, Walker-Bone K, Griffin M, Syddall H, Pannett B, Coggon D, et al. Prevalence and occupational associations of neck pain in the British population. Scand J Work Environ Health. 2001;27:49-56, http://dx.doi.org/10.5271/sjweh.586.

3. Lawrence JS. Disc degeneration: Its frequency and relationship to symptoms. Ann Rheum Dis. 1969;28:121-139, http://dx.doi.org/10.1136/ard.28.2.121.

4. Hogg-Johnson S, van der Velde G, Carroll L, Holm LW, Cassidy JD, Guzman J, et al. The burden and determinants of neck pain in the general population: Results of the Bone and Joint Decade 2000-2010 task force on neck pain and its associated disorders. J Manip Physiol Ther. 2009;32(2):S46-60, http://dx.doi.org/10.1016/j.jmpt.2008.11.010.

5. Webb R, Brammah T, Lunt M, Urwin M, Allison T, Symmons D. Prevalence and predictors of intense, chronic and disabling neck and back pain in the UK general population. Spine. 2003;11:1195-202, http://dx.doi.org/10.1097/01. BRS.0000067430.49169.01.
6. Bergman S, Herrstrom P, Hogstrom K, Petersson IF, Svensson B, Jacobsson LTH. Chronic musculoskeletal pain, prevalence rates, and sociodemographic associations in a Swedish population study. J Rheum. 2001;28:1369-77.

7. Rauhala K, Oiharinen K, Jarvelin M, Raustia AM. Facial pain and temporomandibular disorders: An epidemiological study of the North Finland 1966 birth cohort. Cranio. 2000;18:40-6.

8. Strine T, Hootman J. US national prevalence and correlates of low back and neck pain among adults. Arthritis Rheum (Arthritis Care Res). 2007;57:656-65, http://dx.doi. org/10.1002/art.22684.

9. Cote P, Kristman K, Vidmar M, van Eerd D, Hogg-Johnson $\mathrm{S}$, Beaton D, et al. The prevalence and incidence of work absenteeism involving neck pain. Spine. 2008;33:S192-8, http://dx.doi.org/10.1097/BRS.0b013e3181644616.

10. Gunnarsdottir H, Rafnsdottir G, Helgadottir B, Tomasson K. Psychosocial risk factors for musculoskeletal symptoms among women working in geriatric care. Am J Indust Med. 2003;44:679-84, http://dx.doi.org/10.1002/ ajim.10279.

11. Josepson M, Vingard E. Workplace factors and care seeking for low-back pain among female nursing personnel. Scand J Work Environ Health. 1998;24:465-72, http://dx.doi. org/10.5271/sjweh.370.

12. Miranda H, Kaila-Kangas K, Heliovaara M, Leino-Arjas P, Haukka E, Liira J, et al. Musculoskeletal pain at multiple sites and its effects on work ability in a general working population. Occup Environ Med. 2010;67:449-55, http://dx.doi. org/10.1136/oem.2009.048249.

13. Jang R, Karwowski W, Quesada PM, Rodrick D, Sherehiy B, Cronin SN, et al. Biomechanical evaluation of nursing tasks in a hospital setting. Ergonomics. 2007;50:1835-55, http:// dx.doi.org/10.1080/00140130701674661.

14. Edlich R, Hudson M, Buschbacher R, Winters KL, Britt LD, Cox MJ, et al. Devastating injuries in healthcare workers: description of the crisis and legislative solution to the epidemic of back injury from patient lifting. J Long Term Effects Med 
Implants. 2005;15:225-41, http://dx.doi.org/10.1615/JLongTermEffMedImplants.v15.i2.90.

15. Michie S, Williams S. Reducing work related psychological ill health and sickness absence: A systematic literature review. Occup Environ Med. 2003;60:3-9, http://dx.doi. org/10.1136/oem.60.1.3.

16. Estrynbehar M, Kaminski M, Peigne E, Bonnet N, Vaichere E, Gozlan C, et al. Stress at work and mental health status among female hospital workers. Br J Indust Med. 1990;47:20-8.

17. Windt D, Croft P, Pennix B. Neck and upper limb pain. More pain is associated with psychological distress and consultation rate in primary care. J Rheum. 2002;29:564-9.

18. Rahman A, Reed E, Underwood M, Shipley ME, Omar RZ. Factors affecting self-efficacy and pain intensity in patients with chronic musculoskeletal pain seen in a specialist rheumatology pain clinic. Rheumatology. 2008;47:1803-8, http:// dx.doi.org/10.1093/rheumatology/ken377.

19. Ware J, Kosinski M, Keller S. A 12-Item Short-form health survey. Construction of scales and preliminary tests of reliability and validity. Med Care. 1996;34:220-33, http://dx.doi. org/10.1097/00005650-199603000-00003.

20. Fletcher A, Gore S, Jones D, Fitzpatrick R, Spiegelhalter D, Cox D. Quality of life measures in health care II: Design, analysis and interpretation. BMJ. 1992;305:1145-8, http:// dx.doi.org/10.1136/bmj.305.6862.1145.

21. Yip V. New low back pain in nurses: work activities, work stress and sedentary lifestyle. J Adv Nursing. 2004;46:43040, http://dx.doi.org/10.1111/j.1365-2648.2004.03009.x.

22. Janwantanakul P, Pensri P, Jiamjarasrangi W, Sinsongsook T. Association between prevalence of self-reported musculoskeletal symptoms of the spine and biopsychosocial factors among office workers. J Occup Health. 2009;51:114-22, http://dx.doi.org/10.1539/joh.L8105.

23. Jaworek M, Marek T, Karwowski W, Andrzejczak C, Genaidy AM. Burnout syndrome as a mediator for the effect of work-related factors on musculoskeletal complaints among hospital nurses. Int J Indust Ergonom. 2010;10:368-75, http://dx.doi.org/10.1016/j.ergon.2010.01.006.

24. Eriksen W, Bruusgaard D, Knardhal S. Work factors as predictors of sickness absence: A three month prospective study of nurses' aides. Occup Environ Med. 2003;60:271-8, http:// dx.doi.org/10.1136/oem.60.4.271.

25. Shah D. Healthy worker effect phenomenon. Ind J Occup Environ Med. 2009;13(2):77-9, http://dx.doi.org/10.4103/00195278.55123

This work is available in Open Access model and licensed under a Creative Commons Attribution-NonCommercial 3.0 Poland License - http://creativecommons.org/ licenses/by-nc/3.0/pl/deed.en. 